Pregledni naučni članak

UDK: 711.4(497.11)

351.777.8(497.11)

ID: 212262668

\author{
Nataša Danilović Hristić \\ JUP Urbanistički zavod Beograda, \\ Palmotićeva 30, 11000 Beograd, Srbija \\ natasa.danilovic@urbel.com
}

\title{
URBANA BEZBEDNOST I PREVENCIJA ULIČNOG KRIMINALA KAO PREDUSLOVI ZA RAZVOJ ZDRAVE ZAJEDNICE*
}

\begin{abstract}
Apstrakt: Svetska zdravstvena organizacija (WHO - World Health Organization) svrstava bezbednost zajednice od kriminala u kategoriju prirodnih katastrofa, požara, saobraćajnih i drugih nezgoda, u kojima najvažniju ulogu igra spremnost same zajednice da reaguje, spreči, pomogne ili umanji negativne efekte. Takođe, Međunarodni centar za prevenciju kriminala (The International Centre for the Prevention of Crime) daje čak i širi fokus bezbednosti zajednice, smatrajući je javnim dobrom. Jedna od opšte prihvaćenih definicija „da je bezbednost u osnovi sloboda od pretnji” (Barry Buzan, 1991), daje tumačenje na daleko višem nivou opšte (državne, tj. nacionalne) bezbednosti, ali može se primeniti i na nivo urbane sredine i osećaj koji o prostoru formiraju njegovi korisnici. Osnove za nasilno (kriminalno, seksističko ili rasističko) ponašanje prema određenim kategorijama stanovništva leže u opštoj socijalnoj i ekonomskoj situaciji društva, što se prenosi i na ulice gradova. Realnost i ozbiljnost nasilja na ulicama dovodi do sveukupnog osećaja nesigurnosti u zajednicama, a nesigurnost gradskih prostora izaziva njihovo umanjeno ili pogrešno korišćenje. Sve su češći klinički slučajevi savremene urbane bolesti agorafobije, koja je prvobitno označavala strah od otvorenog prostora, dok se danas pod tim pojmom podrazumeva skup strahova u vezi sa javnim mestima i velikim brojem ljudi, sa strahom da na takvom mestu nakon iznenadnog onesposobljenja ne bi bili u stanju pobeći ili potražiti pomoć. Potrebno je definisati i ustanoviti uslove da bezbednost zajednice postane pozitivan rezultat prevencije nasilja, da se tretira kao aspekt kvaliteta života, u kome su ljudi, individualno ili kolektivno, u najboljoj mogućoj meri zaštićeni od mogućih opasnosti ili pretnji, koje su posledica kriminalnog ili anti-socijalnog ponašanja drugih članova društva. Osećaj nesigurnosti u javnim gradskim prostorima ima dve dimenzije, objektivnu i subjektivnu. Objektivna je podržana realnim događajima u prostoru, a subjektivna je predmet ličnih osećanja građana, zasnovana podjednako na objektivnoj dimenziji, koliko i na pojedinačnom stepenu prihvatanja i podnošenja stvarnosti, slabosti ili hrabrosti, tj. spremnosti da
\end{abstract}


se odupre i suprostavi nasilju u okruženju. Kako će osoba reagovati, zavisi od razvoja njenih osećanja, koja su donekle predodređena društvenim položajem.

Ključne reči: kriminal, zdravlje, zajednica, prevencija $\mathrm{Ne} \mathrm{MeSH}$ : javni gradski prostori, urbana bezbednost

Key words: criminal, health, community, prevention Non MeSH: urban public space, urban safety

\section{Boravak u otvorenom gradskom prostoru kao potreba}

Blagotvorni uticaj na ljudsko zdravlje, kako fizičko tako i mentalno, ima boravak u otvorenom prostoru, koji je prijatan i bezbedan, koji zadovoljava osnovne ljudske potrebe i pruža mogućnosti za nesmetano kretanje, brojne i raznovrsne aktivnosti. [1] Pešačko i biciklističko kretanje su svakako najpoželjniji vidovi mobilnosti, koji imaju rekreativnu i opuštajuću funkciju, doprinose opštem zdravlju pojedinca, ali istovremeno utiču i na smanjenje korišćenja drugih vidova transporta koji emituju zagađenje životne sredine, a jedan od preuslova je obezbeđenje bezbednosti. Iz tog razloga mogu se sagledati jasne veze između urbane bezbednosti i zdravlja zajednice.

Prema Janu Gelu $[2,3]$ postoje tri vrste aktivnosti u otvorenim javnim prostorima, čiji nivo učestalosti definiše kvalitet okruženja:

1. neophodne aktivnosti, kao što je odlazak u školu ili na posao, kupovina namirnica, čekanje autobusa i sl.

2. opcionalne aktivnosti, koje zavise od želje, raspoloživog vremena i pogodnosti prostora, kao što su na primer šetnja, sedenje u parku ili bašti kafea, sunčanje na gradskoj plaži i sl.

3. socijalne ili posledične aktivnosti, koje zavise od količine i kvaliteta prve dve kategorije, a koje podrazumevaju sve međusobne kontakte sa drugim ljudima u prostoru, bilo da ih poznajemo ili ne. Ovi kontakti mogu biti aktivni (razgovor ili igra) ili pasivni (posmatranje i slušanje drugih ljudi)

Kada je kvalitet javnog prostora u kome se provodi slobodno vreme na visokom nivou, stepen opcionalnih aktivnosti takođe raste, što podstiče i broj socijalnih kontakata. Potrebe građana u javnom prostoru mogu se svesti na: [4]

1. komfor u korišćenju, što može imati najrazličitije pojavne oblike, od potrebe da se korisnici osećaju bezbedno do detalja kao što su na primer udobnost parkovskih klupa, ili zasenčenje i provetrenost u predelima koji obiluju suncem. Od komfora često zavisi vremenski period korišćenja prostora: stepenište ispred muzeja može poslužiti kao mesto za sedenje, ali za kratko, samo dok se sačeka prijatelj.

2. relaksaciju tela i uma, što zahteva prirodne elemente poput zelenila, vode i sl. 
3. pasivno korišćenje, tj. posmatranje scena koje se smenjuju u urbanom okruženju, želju da se na ovaj način učestvuje u gradskim dešavanjima, potrebu da se vidi i bude viđen.

4. aktivno korišćenje, tj. druženje sa drugim ljudima, kupovina na zelenim pijacama, učestvovanje u manifestacijama (koncerti, proslave, demonstracije) i sl.

5. otkrića ili želju koja stimuliše i nosi novo i prijatno iskustvo. Ova potreba se može zadovoljiti kretanjem kroz prostor i otkrivanjem novih prostora, ili novih aspekata, promena i detalja već poznatih.

\begin{tabular}{|c|c|}
\hline osnovne ljudske potrebe & karakteristike i zahtevi za javne gradske prostore \\
\hline socijalna pripadnost & $\begin{array}{l}\text { udobni i sigurni prostori za susret, prostori koji } \\
\text { imaju atribute koji podstiču na druženje, podstiču } \\
\text { komunikaciju }\end{array}$ \\
\hline kulturni i kolektivni smisao & $\begin{array}{l}\text { prostori za kulturne manifestacije i proslave, ma- } \\
\text { sovna okupljanja, simboli pripadnosti i identiteta, } \\
\text { osećaj jedinstvenosti }\end{array}$ \\
\hline $\begin{array}{l}\text { relaksacija i psihološko } \\
\text { opuštanje }\end{array}$ & $\begin{array}{l}\text { mirni prostori sa niskim nivoom senzualne stimu- } \\
\text { lacije, povezanost sa prirodom, klupe za sedenje ili } \\
\text { staze za šetanje vizuelno orijentisane ka pejzažu }\end{array}$ \\
\hline $\begin{array}{l}\text { potreba sa privatnošću, } \\
\text { kombinacija međuljudskih } \\
\text { interakcija i osamljenosti }\end{array}$ & $\begin{array}{l}\text { zaklonjenost i intima pojedinih mesta, mogućnost } \\
\text { stvaranja distance između korisnika }\end{array}$ \\
\hline $\begin{array}{l}\text { proces učenja, saznanja i } \\
\text { podele informacija }\end{array}$ & $\begin{array}{l}\text { mesta susreta i razmene, cirkulacije i razgovora, } \\
\text { dobra akustika i vizuelna preglednost prostora, ra- } \\
\text { zličiti organizovani i javni programi i manifestacije, } \\
\text { neometanje drugih korisnika }\end{array}$ \\
\hline $\begin{array}{l}\text { veza sa prirodom i } \\
\text { prirodnim elementima }\end{array}$ & $\begin{array}{l}\text { otvoren prostor, dnevno svetlo i osunčanost, svež i } \\
\text { zdrav (nezagađen) vazduh, ventilacija, provetrenost, } \\
\text { biljke (trava, drveće), životinje (psi, mačke, ptice, } \\
\text { veverice i sl.), prirodni materijali (kamen, drvo, } \\
\text { pesak). }\end{array}$ \\
\hline $\begin{array}{l}\text { taktilni osećaj, nadražaj } \\
\text { senzora i čula }\end{array}$ & $\begin{array}{l}\text { materijali različite strukture i teksture, varijacija } \\
\text { boja, mirisi }\end{array}$ \\
\hline $\begin{array}{l}\text { prijateljsko i prirodno audio } \\
\text { okruženje }\end{array}$ & $\begin{array}{l}\text { zvuci prirode (šum talasa, lišća, pevanje ptica) i } \\
\text { glasovi ljudi, bez buke }\end{array}$ \\
\hline $\begin{array}{l}\text { interesovanje za vizuelno } \\
\text { okruženje i potreba za } \\
\text { estetskim elementima }\end{array}$ & $\begin{array}{l}\text { prihtvatanje dizajna inspirisanog prirodom, organ- } \\
\text { skih formi, smanjenje monohromatskih šema }\end{array}$ \\
\hline $\begin{array}{l}\text { ispunjenje i traganje za } \\
\text { smislom }\end{array}$ & reperi, preglednost, orijentacija, opšta slika prostora \\
\hline
\end{tabular}




\begin{tabular}{|l|l|}
\hline \multicolumn{1}{|c|}{ osnovne ljudske potrebe } & karakteristike i zahtevi za javne gradske prostore \\
\hline vežbanje, fizička aktivnost & $\begin{array}{l}\text { staze za trčanje, penjanje, vožnju biciklom, jahanje, } \\
\text { otvoreni sportski tereni, podsticanje istraživačkog } \\
\text { duha }\end{array}$ \\
\hline osećaj jednakosti & $\begin{array}{l}\text { podjednaka orijentisanost ka svim korisnicima kroz } \\
\text { primenu principa pristupačnosti }\end{array}$ \\
\hline
\end{tabular}

Tabela 1: Veze između osnovnih ljudskih potreba i okruženja u vidu javnih gradskih prostora

Među ljudskim nagonima, potreba za osećajem sigurnosti i bezbednosti zauzima veoma visoko mesto, odmah iza osnovne potrebe za preživljavanjem. Prostor i njegova pojavna vrednost mogu značajno da utiču, podstiču ili obeshrabruju, socijalne kontakte i emocijalne doživljaje korisnika. Uređeni i osvetljeni prostori u kojima ima korisnika destimulativni su za antisocijalna ponašanja, vandalizam i delikvenciju. Način na koji se i najsitniji elementi „razmeštaju” u prostoru (na primer elementi urbanog mobilijara, kao što su klupe, rasveta i sl.) utiče na vrstu socijalnog kontakta, tj. prostoru daju „sociopetalni” ili „sociofugalni” karakter. [5] Kada su elementi prostora orijentisani jedni ka drugima, u položaju koji omogućava i podstiče socijalni kontakt (pogled ili razgovor) govorimo o sociopetalnom prostoru. Ako su korisnici prinuđeni da koriste prostor tako što su udaljeni jedni od drugih, sakriveni ili okrenuti leđima, onda je prostor izgubio svoju društvenu važnost i nazivamo ga sociofugalnim.

Tema uticaja dizajna javnog prostora na ljudsko ponašanje bila je predmet više istraživanja. Na primer, Mičelson [6] ispituje ovaj odnos kroz psihološke varijable stanovnika koji koriste prostor, sociološke varijable vezane za formalnu ili neformalnu organizaciju društvenih grupa u prostoru i kulturološke varijable, koje se odnose na verovanja, vrednosti, običaje, pravila i ukuse koji rukovode društvenim životom u posmatranoj okolini. Rezultat studije je da u situaciji kada grupe građana mogu slobodno da izaberu karakteristike javnih prostora, preferiraju one koji se poklapaju sa njihovim socio-kulturološkim ili psihološkim odlikama, a koriste ih prema sopstvenim kulturološkim obrascima. Jedno od najboljih rešenja je raznovrsnost ponude javnih prostora, u smislu njihove multifunkcionalnosti, karaktera i opremljenosti.

\section{Aspekt urbane bezbednosti i uticaj na svakodnevni život građana}

Nažalost, u javnim gradskim prostorima dešavaju se i negativne pojave, pre svega vezane za nedostatak ljubavi prema gradu, nemogućnost indetifikacije sa njegovim simbolima, kao posledica protesta i gneva, nepronalaženja sopstvenog mesta, antisocijalnog ponašanja, vandalizma i obesti. Nasilje i strah ponekada preuzimaju vlast nad gradskim prostorom, u vidu „ratova” bandi, kartela i huligana, a to je upravo ono što se ne sme dozvoliti. Uloga grada je da se približi svojim građanima, da ih edukuje, nauči ponašanju i poštovanju, ali u isto vreme da pruži kvalitetnu ponudu, lepe i sigurne ambijente u kojima će se počinioci vandalskih dela osećati nemoćnima, 
a svako neprimereno ponašanje primetiti i sankcionisati. Nesigurnost dovodi do veće degradacije grada i finalno do napuštanja nekih njegovih delova, bilo da ih napuštaju građani koji to mogu sebi da priušte, bilo da ih napuštaju delovi institucionalizovanog sistema (službe koje čiste i održavaju grad, javni gradski i taksi prevoz, ponekada čak i policija).

Postizanje bezbednosti građana u javnim gradskim prostorima suštinski balansira između dva krajnja koncepta: ideje o ravnopravnosti svake vrste (uključujući i rasnu, polnu ili ekonomsku ravnopravnost) i potrebe kontrole, nadzora i osmatranja. Imajući sa jedne strane liberalne, pomalo idealističke, levičarski obojene zahteve, a sa druge strane metode koje asociraju na desničarske i totalitarne, zadatak pronalaženja prave mere i načina obezbeđenja bezbednog okruženja, nije nimalo lak. Iz tog razloga prednost se daje prostornim rešenjima, tj. urbanističkim i arhitektonskim intervencijama koje su se pokazale kao vrlo uspešne, posebno u smislu prevencije.

Sam grad kao tvorevina, sa aspetka bezbednosti, danas predstavlja kontradiktornost. Veliki paradoks leži u istorijskoj činjenici da je jedan od najjačih razloga nastanka i ekspanzije gradova potreba za sigurnošću. Međutim, savremene urbane sredine, ili neki njihovi delovi, često predstavljaju oličenje opasnosti. Osnovna uloga grada kao socio-ekonomskog centra ostaje, ali se njegova slika menja. Iako je uvek prisutna nostalgija za društvom i zajednicom kakvi su nekada bili (prepoznatljivi, bliski, bezbedni i sl.), grad se mora prihvatiti kao živ organizam, koji raste, menja se, čini greške, uči na njima. Gradovi ne nastaju i ne razvijaju se sami od sebe, oni su produkti ljudske volje, želje i pre svega potrebe. Kako i koliko se toleriše nesigurnost i rizik u gradskom okruženju, pitanje je kulture, ideologije i veze sa politikom. [7] To suštinski znači i da je realan stepen ne/sigurnosti produkt ljudske zajednice, a ne fizičke strukture grada. On je direktni rezultat ponašanja njegovih sopstvenih stanovnika, korisnika, građana, kako god ih nazivali, njihovih ustaljenih radnji, kretanja, načina života u suštini. Njihove rutinske aktivnosti u gradskom okruženju su svakodnevni izvori, uzroci ili posledice vezane za bezbednost drugih su-korisnika prostora. Grad, ako ga pojednostavljeno posmatramo, predstavlja scenografiju u kojoj se sve dešava, ali ne sme se zanemariti da ova kompleksna tvorevina svojim karakterom i ambijentom, može da pruži povod ili pogodnost za incidente, koji mogu imati efekte na zdravlje stanovnika, da dovedu do njihovog fizičkog povređivanja, u nekim tragičnim slučajevima i do smrtnog ishoda, i svakako do psihičkih trauma zbog doživljenih neprijatnosti.

Uticaj teme bezbednosti na svakodnevni život građana, njihove navike i spremnost da se sa problemom narastajuće opasnosti izbore na više ili manje demokratski način, svakako nije zanemarljiv. Na pitanje zašto su neki gradovi bezbedniji od drugih, ili zašto pojedini delovi grada ulivaju strah, nije lako odgovoriti, jer to podrazumeva veoma detaljan presek socio-ekonomske i političke situacije, ali i podneblja i mentaliteta ili uticaja specifičnih namena (velikih luka, industrijskih kompleksa, vojnih baza i sl.). Siromaštvo, nezaposlenost, ratno okruženje, generalno nezadovoljstvo svojim položajem u društvu i otuđenost, sigurno brže i lakše stvaraju uslove za 
nebezbednu zajednicu u kojoj preti opasnost na ulici. Sa druge strane, mir, blagostanje i uređenost sistema daju osećaj komfora i opšte sigurnosti. Beograd, prolazeći kroz različite faze, od „uljuljkanog” socijalističkog miljea, do nasilnih godina kada su ulicama vladali crno tržište i kriminal, kroz tranzicione muke i napore da se približi ostatku Evrope, dobar je primer kako se pojam bezbednosti može menjati, drugačije shvatati, tumačiti, doživljavati ali i ceniti. Ipak, možda najvažniji je lični osećaj, koji svako od nas ponekada doživi, u trenucima kada sami, noću prolazimo ulicama grada, bez straha za sopstvenu bezbednost, ili suprotno tome, osluškujući korake iza nas, tražeći prometnije i osvetljenije staze, ubrzavajući korak.

Problemi kao što su siromaštvo, nezaposlenost, velike socijalne razlike, zloupotreba droga i opijata, prostitucija, nasilje u kući, huligansko ponašanje na utakmicama, najrazličitija devijantna ponašanja, bezbednost u saobraćaju i nasilnička vožnja i slične negativne društvene pojave kao i uspešnost otkrivanja počinioca, funkcionisanje pravosudnog sistema [7] i politika kažnjavanja izgrednika, ${ }^{1}$ svakako su značajni generatori i posledice nasilničkog ponašanja koje se prenosi ili direktno odvija na gradskim ulicama. Grad tako postaje scenografija za sve vrste kriminalnih radnji, a poslednjih godina strah od terorizma u nekim sredinama postaje jedan od dominantnih. Sveži primeri terorističkih napada na civilne ciljeve u Tokiju (20. 03.1995. gušenje gasom sarinom u metrou), Nju Jorku (11. 09. 2001. avionski napad Alkaide na Svetski trgovinski centar), Madridu (12. 03. 2004. eksplozija na železničkoj stanici Atoća), Londonu (07. 07. 2005. eksplozija u autobusu i liniji metroa), ili oni koje već godinama sprovode organizacije PLO, IRA i ETA, postavljaju veliki izazov pred društvo koje teži otvorenosti i slobodi. [8]

\section{Globalni razvoj ideje urbane bezbednosti i uspostavljanje veze sa zdravljem zajednice}

Koordinisani rad na postizanju bezbednosti u urbanim zajednicima ima kratku istoriju. U SAD kasnih šezdesetih godina XX veka „Rat protiv siromaštva” je doprineo da gradovima bude dodeljen novac iz federalnog budžeta sa svrhom prevencije nasilja, poboljšanja rada lokalnih policija i razvoja socijalnih mehanizama. Tokom sedamdesetih nastaje i jača pokret protiv nasilja nad ženama, uvodeći multidisciplinarni pristup problemu urbanog nasilja i aspektima prevencije. U Danskoj se započinje sa nacionalnim programom za prevenciju urbanog nasilja 1972, a u Švedskoj je sličan koncept promovisan 1974. U Francuskoj se 1982. usvaja program (Bonnemaison programme) na nacionalnom nivou, ali koji se sprovodi na lokalnim nivoima i fokusira se na probleme poput nasilja i delikvencije mladih u urbanim sredinama. $\mathrm{U}$ isto vreme u Kanadi, u Torontu i Montrealu, pokreće se „Ženska inicijativa za bez-

1 Pravosudni sistem ne može uvek adekvatno da odgovori na akte nasilja, globalno gledano, samo mali procenat prestupa, manje od 10\%, stiže pred sud. Istraživanje sprovedeno u Francuskoj 1999. otkriva podatak da policija uspeva da reši manje od $15 \%$ krađa i manje od $10 \%$ nasilja, te da se oko $80 \%$ slučajeva "arhivira" jer počinioci nikada nisu otkriveni. [7] 
bednost" koja deluje takođe na lokalnom nivou. Stvaraju se i regionalne organizacije poput Evropskog foruma za urbanu bezbednost (European Forum on Urban Safety), koji je osnovan posle dve evropske konferencije o ulozi prevencije urbanog nasilja, u Strazburu 1986. i Barseloni $1987 .^{2}$

U poslednjoj dekadi dvadesetog veka počinju da se organizuju konferencije na ovu temu, izdaju se brojne publikacije, članci, knjige preporuka i udžbenici, a međunarodna tela počinju da obraćaju pažnju na važnost koordinisane zaštite zajednice od nasilja. Prva konferencija na kojoj su učestvovali zajednički predstavnici Evrope i Severne Amerike, održana je u Montrealu 1989, što je 1994. dovelo i do osnivanja Međunarodnog centra za prevenciju kriminala (International Centre for the Prevention of Crime - ICPC), koga podržavaju nacionalne vlade nekoliko zemalja sa visokim nacionalnim dohotkom.

Svetska zdrastvena organizacija, koja ima mandat da brine o zdravlju i dobrostanju, započela je 1989. godine Program za bezbednost zajednice, sa naglaskom na prevenciji. Posle nekoliko godina delovanja, 1996. urbano nasilje je i zvanično „priznato" kao problem koji konstantno narasta, pa je iz tog razloga pokrenuta globalna kampanja za prevenciju, koja podrazumeva i sprovođenje istraživanja, objavljivanje publikacija, organizaciju edukacije i treninga. ${ }^{3}$ Organizacija za ekonomsku saradnju i razvoj (Organisation for Economic Co-operation and Development - OECD) inicira konferenciju u Parizu 1994. sa temom života žena u gradovima, što vodi do naredne konferencije o bezbednosti žena u Montrealu 2002. i uspostavljanju nagrade za najbolja rešenja postignuta u praksi sa temom bezbednosti žena u urbanim zonama. [Women's Safety Awards competition]

Na devetom kongresu UN posvećenom temi prevencije nasilja, koji je održan u Kairu 1995, razvijene su smernice koje su kasnije primenjivane na lokalnim nivoima, uz izvesne dopune. Program „Sigurniji gradovi” (UN Habitat; The Safer Cities Programme) je osnovan već naredne godine (1996) sa ciljem da pomogne zemljama u razvoju u postizanju standarda urbane bezbednosti. Postoje još dve organizacije u okviru UN koje se indirektno bave ovim problemom, to su UN Kancelarija za droge i kriminal, osnovana 1997, čiji fokus je na transnacionalnom organizovanom kriminalu i UN Fond za žene, osnovan 1995, koji se koncentriše na polnu jednakost, prevenciju nasilja nad ženama, trafiking, ali i pitanja siromaštva, odnosa prema obolelima od HIV virusa i sl. Do nedavno ove agencije UN nisu imale zajedničkih projekata. Još jedan ogranak UN-a, Fond za žene, se bavio ovom temom, sa osvrtom na problem polne nejednakosti i ugroženosti žena u gradskim sredinama, organizujući Drugu

2 European Forum on Urban Safety (EFUS) je regionalna nevladina organizacija koja sarađuje sa preko 16 nacionalnih i 300 lokalnih vlasti na povećanju bezbednosti u urbanim sredinama. Osnovao ju je 1987. Francuski političar Gilbert Bonnemaison. Da bi se priključili ovom programu lokalne uprave moraju da dokažu da poseduju koalicioni dogovor za postizanje urbane bezbednosti između javnog, privatnog i volonterskog sektora.

3 The World Health Organization (WHO); Community Safety Programme, Global Campaign on Violence Prevention, Department of Injuries and Violence Prevention 
međunarodnu konferenciju o bezbednosti gradova za žene i devojke 2004. u Bogoti, glavnom gradu Kolumbije (United Nations Fund for Women - UNIFEM; Second International Conference on Safer Cities for Women and Girls). Po pitanju razvoja legislative, UN su razvile međunarodni okvir zakona vezanih za ljudska prava, na primer Međunarodna konvencija o pravima dece usvojena je 1989, a slične poruke sadrži i Deklaracija o eliminisanju nasilja nad ženama iz 1993. Naravno postoji i ograničenje vezano za primenu ovih dokumetana, a to je činjenica da ih nisu potpisale sve zemlje članice, da su ih neke potpisale sa rezervom, te da ne postoji telo koje bi vršilo monitoring primene, već se samo objavljuju godišnji izveštaji (The International Convention of the Rights of the Child; The Declaration on the Elimination of Violence against Women).

Od skupova organizovanih u prethodnoj deceniji, trebalo bi još pomenuti da je Sekretarijat Komonvelta (The Commonwealth Secretariat) 2003. organizovao regionalne radionice na temu eliminacije nasilja baziranog na polnoj razlici. Svetski urbani forum (World Urban Forum) održan u Vankuveru 2006, takođe se bavio ovom temom. Tom prilikom je zaključeno da urbanističko planiranje može da razreši ili barem ublaži konflikte u prostoru na lokalnom nivou, i to prvenstveno kroz demokratski vođenu politiku upravljanja prostorom. Potrebno je promovisati socijalno uključenje građana i obezbediti bolje infrastrukturno opremanje i održavanje, kao i brzu reakciju na nastale situacije i ponovnu izgradnju i jačanje zajednica i institucionalnih kapaciteta za planiranje. Takođe, održani su skupovi na tlu Evrope, u Sarajevu $2003^{4}$, u Saragosi 2006, Budimpešti 2008, Tuluzu i Hanoveru 2009, što svakako govori o velikom interesovanju i aktuelnosti.

U Velikoj Britaniji, koja je možda i najdalje otišla u sferi istraživanja i primene praktičnih mera, bezbednost zajednice je definisana kao pozitivan rezultat prevencije nasilja, kao aspekt kvaliteta života, u kome su ljudi, individualno ili kolektivno, u najboljoj mogućoj meri zaštićeni od mogućih opasnosti ili pretnji, koje su posledica kriminalnog ili anti-socijalnog ponašanja drugih članova društva. [9] Na pitanje gde su trenutno najjači i najaktivniji pokreti za urbanu bezbednost, osim već razvijene Evrope, Severne Amerike i Australije, u kojima se inicijativa prvi put i javila, odgovor je da su to zemlje Latinske Amerike i podsaharski deo Afrike. Razlog za to je stanje je visoki nivo urbanog nasilja u ovim sredinama, veličina i mnogoljudnost njihovih gradova, usmeravanje sredstava međunarodnih organizacija upravo za rešavanje problema u ovim regijama, ali i izvesna lingvistička prednost u odnosu na azijski kontinent, tj. rasprostranjeno korišćenje španskog, engleskog i eventualno francuskog jezika, na kojima je objavljeno najviše dokumenata, priručnika i upustava za suzbijanje i prevenciju urbanog nasilja.

4 Konferencija je bila posvećena kulturnoj i religijskoj raznovrsnosti, a pojedina istraživanja i izlaganja su se bavila temom gradova, tj. zašto su urbane sredine postale centri konflikta i šta su to enklave mira i bezbednosti. Jedan od zaključaka je da treba promovisati polikulturalne i multifunkcionalne javne prostore, kao lakše odbranjive i održive. 


\section{Cena urbanog nasilja i degradacija kvaliteta života}

Iako se ne može sporiti da ljudski život nema cenu, mora se sagledati i ekonomski aspekt ne/bezbednosti u javnim gradskim prostorima. Za početak, nasilje i strah od njega podrivaju demokratičnost društva. Na primer, samo u Južnoj Africi postoji tri puta više privatnih čuvara i pripadnika obezbeđenja nego institucionalnih organa reda, odnosno policije. Trebalo bi istaći da su oni uglavnom naoružani i da nemaju nikakav stepen odgovornosti i obaveza prema javnosti, jer nisu finansirani iz budžeta. [9]

Bezbednost je jedan od najčešće korišćenih kriterijuma za rangiranje kvaliteta života u gradu, [10] sa stanovišta tržišne konkurencije gradova [10] i međunarodnih investicija, a većina studija je ukazala na pad tržišnih vrednosti u zonama koje su okarakterisane kao opasne (to se podjednako odnosi na pad cena nekretnina kao i na pad prometa i zatvaranje radnji i kancelarija). [9] Jedan od najboljih pregleda „cene” nasilja se zasniva na nedavnom istraživanju koje je sprovedeno u zemljama niskog nacionalnog dohotka i životnog standarda, uglavnom u Latinskoj Americi. [9] Ovaj model kombinuje zdravstveni, socijalni, ekonomski i prostorni uticaj, od individualnog do društvenog nivoa. Konkretno, fokusira se na četiri kategorije „kapitala”:

1. Finansijski, koji obuhvata nekretnine, poslovanje i ušteđevine. Nasilje je često inspirisano i usmereno ka ovim elementima. U cilju zaštite pribegava se pojedinačnim merama (zaštita nekretnina ogradama, alarmima i sl.) ili merama koje sprovodi društvo iz budžetskih sredstava (pojačano patroliranje policije, povećanje troškova za odsluženje kazni u za to predviđenim ustanovama)

2. Ljudski, obuhvata individualno i kolektivno investiranje u obrazovanje i zdravstveni sistem. Nasilje vodi ka povređivanju (fizičkom ili psihičkom), što umanjuje šanse za napretkom, boljim obrazovanjem, zaposlenjem i uključenjem u društvo

3. Prirodni, koji obuhvata prirodne ali stvorene odlike jedne sredine. Kao ilustracija može da posluži veza između straha od nasilja i zagađenja prirodne sredine. Na primer, zbog straha stanovnici izbegavaju da koriste sredstva javnog prevoza i opredeljuju se za automobile, što povećava emisiju izduvnih gasova.

4. Socijalni, koji podrazumeva skup društvenih normi i standarda ponašanja, kao i stepen poverenja i interakcije u zajednici. Nasilje erodira poverenje i saradnju, poništava ljudska prava i umanjuje učešće $u$ formalnim ili neformalnim organizacijama civilnog društva.

Baveći se dokazivanjem da je raznolikost u kontekstu grada apsolutno pozitivna i poželjna, Fil Vud i Čarls Landri [11] pozivaju se na ranija istaživanja Džejn Džekobs, koja je prva zauzela stav da raznolikosti tj. raznovrsnosti predstavljaju vodeće potencijale i komparativne prednosti u dugoročnom razvoju grada; zatim na razmatranja Pitera Hola, koji ističe vezu između kreativnosti i dinamičnosti gradova, 
te ukazuje na atraktivnost i privlačnost gradova za doseljenike i stvaranje tenzije između grupa stanovnika; osim toga, pozivaju se i na teoriju Ričarda Floride, da će $\mathrm{u}$ "takmičenju” gradova pobediti oni koji su u stanju da privuku i zadrže kreativne stanovnike (tz. kreativnu klasu) i koji su najtolerantniji. Tako se dolazi do zaključka da migracija čini grad kompetativnijim i konkurentnim, a ne da kompetativni gradovi privlače migraciju. Brza i uspešna integracija emigranata je ključ uspeha i zahteva strateški plan „inerkulturalnog grada za sve”. [11]

Gde se i zašto javlja segregacija stanovništva i zašto predstavlja fazu u razvoju grada? Iako većina Evropljana sebe smatra tolerantnim i opredeljenim za jednakost kao princip, događaji koji se povremeno dese u nekom od evropskih gradova ili evidentno postojanje delova grada koji se mogu okarakterisati kao geta ili enklave, govore suprotno. Podeljenost zajednice, segregacija na različite kulture, jezike, religije, nivoe obrazovanja ili lične zarade, dovodi do fragmentacije društva i vođenja „paralelnih" života različitih grupa u okviru svojih ograničenih prostora. [11, 12] Etničke, [11] rasne, religijske i sl. zajednice koje su koncentrisane u okviru definisanog prostora, imaju veće šanse da iskuse socijalnu i ekonomsku izolaciju i daleko manje šanse za povezivanje sa ostatkom društva i deljenje sistema vrednosti i osećaja građanske pripadnosti. [7] Stigma bazirana na razlikama u rasi, religiji, etničkoj pripadnosti, seksualnoj orijentaciji i sl. nosi visok rizik od izloženosti nasilju.

Nasuprot segregaciji stoji integracija i socijalna izmešanost. Ovo je odlika kosmopolitskih gradova u kojima se pored neizbežne segregacije odvija i jak proces asimilacije stanovništva, prihvatanja zajedničkih standarda i normativa, međusobne razmene i stalne interakcije između građana. Međusobne različitosti umesto problema postaju prednost i potencijal, a pravo na korišćenje prostora ostvaruju svi podjednako i istovremeno. Dakle, savremeni grad je konglomerat kontrasta i različitosti u kome manjine ne treba da imaju osećaj isključenosti. Za postizanje socijalne harmonije i stabilnosti, presudno je rešavanje konflikta i promocija tolerancije razlika. Javna bezbednost i koezistencija, tj. deljenje zajedničkog života u urbanoj sredini su svakako povezane, što dokazuju brojna istraživanja sprovedena u urbanim zonama.

\section{Lični osećaj bezbednosti}

Svako doba nosi svoje strahove, a naše doba je dodatno opterećeno medijima koji prenose i uvećavaju strah do nivoa masovne paranoje. Samo na osnovu podatka da se upotreba reči „strah”, „rizik”, „opasan/opasnost” u novinskim člancima u istraživanom periodu od 1996. do 2006. uvećala u proseku za oko 50\%, može se zaključiti koliko je javnost opterećena. Osim medija koji se bave opasnostima svakodnevnice, veliku ulogu ima i politika, jer se strah pokazao kao jedno od najboljih sredstava u političkom diskursu. [13] Da se današnje društvo može nazvati „kulturom straha i rizika" sigurno je doprinelo ne samo uvećanje samih rizika, već i povećanje saznanja i svesti o svemu što se oko nas dešava ili bi se moglo desiti, o svim faktorima koji izazivaju osećaj nesigurnosti, ugroženosti i nebezbednosti. 
Da li je osećanje nesigurnosti u gradovima još jedan od urbanih mitova ili realnost? Strah koji proizvode pojedini delovi grada ili koji osećaju pojedine društvene grupe u određenim periodima dana nije novina. Kao dokaz može da posluži izvod iz pisma koje je 1730. Daniel Defo, autor romana „Robinzon Kruso”, uputio gradonačelniku Londona: „Ceo grad, gospodine, je uzbuđen i unesrećen. Građani se ne osećaju bezbednima u svojim kućama, niti na ulicama; pljačkaju ih, vređaju i maltretiraju... I ovi prestupi se čine u toku vaše vlasti, kao nikada ranije (u svakom slučaju ne sa takvom učestalošću) i ako nastave biće potrebno pozvati vojsku, dok se sa tim ne okonča." [7]

Dakle, sigurnost u gradovima nije samo problem savremenog društva i njegovih institucija, već nam ovaj kratak citat ukazuje na dugotrajan proces. Međutim, danas je pitanje osećaja nedostatka bezbednosti postalo odličan izgovor za izbegavanje zajedničkog života sa svim onim osobama koje „ne liče” na nas. Antiurbani pokret koji se proširio u SAD vezuje grad uz pojmove kao što su rizik, opasnost i nesigurnost. Ali pravi odgovor na nasilje nije kupovina oružja ili preseljenje u hiperzaštićenu sredinu. Glasine, mitovi i strahovi se najbolje eliminišu suočavanjem, vođenjem javnih debata, pokretanjem akcija, uključivanjem stanovnika i naravno, aktivnim i namenskim korišćenjem javnog prostora. Ako nasilje duži period vlada nekim delom grada, posebno ako je u pitanju zajednica na margini društva, izložena segregaciji, stanovnici će se povući u sebe, u bezbednost svojih kuća. Kada se članovi jedne zajednice ne poznaju, oni se vrlo lako međusobno optužuju, stigmatizuju ili smatraju opasnima. Ako dodatno postoji ideološka stimulacija rasizma i ksenofobije, grad ili njegovi pojedini delovi postaju veoma ranjivi. Logično, nema ni novih stanovnika ili turista, jer loš imidž i strah brzo prevazilaze granice.

Baveći se „ekologijom straha” Dejvis istražuje promene urbanih formi koje su nastale pod uticajem straha od urbanog nasilja, kao i izmenu socijalnih veza i ponašanja građana. Istražujući na primeru Los Anđelesa i Orlanda, utvrđuje da su različiti socijalni miljei u stanju da razviju sopstvene strategije i mehanizme, a pre svega u formi izolacije od drugih društvenih grupa od kojih osećaju ugroženost. Tako nastaju zatvorene/ograđene zajednice, a obezbeđenje dobija veći značaj u procesu kreiranja urbanih prostora. Povećanje fizičke i socijalne zatvorenosti vodi potpunoj privatizaciji javnih prostora. Gradovi postaju podeljeni na eklave, u kojima grupe stanovnika žive bez međusobnih kontakata. [10] U svetu informatičkog doba, koji je umrežen internetom, u kome su savladane sve granice, razdaljine i razlike, ovo postaje apsurd.

Osećaj nesigurnosti u javnim gradskim prostorima ima dve dimenzije, objektivnu i subjektivnu. Objektivna je podržana realnim događajima u prostoru, a subjektivna je predmet ličnih osećanja građana, zasnovana podjednako na objektivnoj dimenziji, koliko i na pojedinačnom stepenu prihvatanja i podnošenja stvarnosti, slabosti ili hrabrosti, tj. spremnosti da se odupre i suprostavi nasilju u okruženju. Kako će osoba reagovati zavisi od razvoja njenih osećanja, koja su donekle predodređena društvenim položajem. U aktuelnom stanju koga karakteriše proces globa- 
lizacije stanovništvo se, prema Patriku Hebrehtu, [7] deli na kompetativni deo od $40 \%$, deo kome preti marginalizacija od približno $30 \%$ i marginalizovani deo od $30 \%$. Kompetativni deo društva ima mogućnost i sposobnost za stvaranje novih socijalnih veza, ova grupa se identifikuje sa novom globalnom kulturom, a na ideološkom planu na nju utiče koncept neoliberalnog morala. Jednostavno rečeno, ovaj deo društva sebi može da obezbedi svu potrebnu zaštitu i ostvari osećaj sigurnosti, pre svega preko privatnih službi za bezbednost i dobrovoljnom izolacijom u zasebnim naseljima. Druga društvena grupa koju ugrožava ekonomska marginalizacija, u opasnosti je da iskusi isti proces i na socijalnom, kulturnom i političkom nivou. Oni se osećaju ugroženim od aspekata nasilja i napuštenim od strane države, predstavnika policije i sudstva. Konačno, treća grupa koja je već na margini društva prima najveće uticaje negativnih efekata globalizacije, nju čine oni koji se nikako ne uklapaju u većinsku sliku društva i njihov izlazak iz tog zatvorenog kruga je gotovo nemoguć.

Uspostaviti jasan odnos između realnih slučajeva nasilja i ličnog osećaja bezbednosti nije nimalo lako. Rizik i strah mogu biti opravdani ili ne, izazvani ili umišnjeni, ali bez obzira na njihovo poreklo i osnovanost, čine da pojedinac ili zajednica promene svoje navike i načine korišćenja javnih gradskih prostora. Čak ni sprovođenje anketa u cilju istraživanja ovog fenomena neće uvek dati realne rezultate, ali može ukazati na neke generalne strahove građana. Na primer, primećeno je da ispitanici muškog pola teže „priznaju” strah od nasilja jer to smatraju sopstvenom slabošću, dok ispitanice ženskog pola daleko više percipiraju rizične situacije u prostoru, čak u nekim slučajevima i preteruju. Studija sprovedena u Edinburgu (Škotska, VB) je otkrila da 83,8\% ispitanih žena izbegava određene gradske ulice ili zone, da 70,1\% žena izbegava pojedine vidove transportnih sredstava, da 35\% žena ponekada ili uvek izbegava da izlazi iz kuće sama jer se plaši seksulnog napada. Takođe je utvrđeno da strah od seksualnog napada utiče na poslovni-radni deo života $41,6 \%$ ispitanica, odnosno 53,6\% misli da im je ovim strahom ugrožen način provođenja slobodnog vremena, a 76,9\% smatra da strah utiče na njihov socijalni život. Imajući ovo u vidu, postavlja se pitanje zašto se deci ženskog pola od najranijeg detinjstva daju instrukcije da se plaše nepoznatih ljudi, dok se adolescentni dečaci ohrabruju da negiraju ranjivost i da ne ispoljavaju strah. [9]

\section{Zaključak}

U svakom slučaju, preko 20 godina intezivnog istraživanja upućuje na zaključak da postoji kompleksna i zavisna veza između nasilja, izazvanog straha, ličnog osećaja nesigurnosti i promene ponašanja subjekata u prostoru. Sa stanovišta pojedinca ili zajednice, javlja se strah za sopstvenu bezbednost i sigurnost članova porodice, umanjuje se mobilnost, gubi želja za napuštanjem prostora koji je percipiran kao siguran (obično kuća/stan, najbliže susedstvo, deo grada). Korišćenjem strategije limitiranja sopstvenog kretanja i boravka u određenim javnim prostorima umanjuju se šanse za bolje obrazovanje, zaposlenje ili korišćenje slobodnog vremena, gubi se poverenje u 
zajednicu, susede ili institucije, a sve zajedno može da dovede do depresivnih stanja i konstantnog nezadovoljstva. Gledano sa prostornog aspekta, javni gradski prostori postaju napušteni, izbegavani, prepušteni sami sebi i potpuno okupirani negativnim i nepoželjnim sadržajima, dešavanjima ili korisnicima i u tom smislu potpuno neadekvatni svojoj osnovnoj nameni: da služe podjednako svima, na opšte zadovoljstvo. Iz tog razloga se i strah od nasilja dovodi u direktnu vezu sa fenomenom javnih prostora. Sa druge, ekonomske strane, ovo otvara prostor za intezivan razvoj privatnih kompanija za obezbeđenje ljudi i imovine, a za one koji to sebi mogu da priušte, život se „seli” na neke druge, poželjnije lokacije, koje imaju poseban režim zaštite i izolovanosti.

Sa socijalnog aspekta, stvaranje "ograđenih zajednica” (eng. gated commuunities) vodi segregaciji društva, još većoj netrpeljivosti prema vidljivim manjinama, strancima, beskućnicima i sl. Globalno gledano dolazi do smanjivanja osnovnog ljudskog prava na slobodu i slobodno kretanje. Neki autori [9] smatraju da pojam „prava na grad" ne podrazumeva samo osećaj udobnosti i dobrodošlice u javnom gradskom prostoru, već ima značajan uticaj na fizičku strukturu i socijalne odnose koje se stvaraju u gradskom okruženju. Gubitak ovog prava vodi ka nedostatku mogućnosti slobodnog kretanja, nekoj vrsti „kućnog pritvora”, što je grubo kršenje ljudskih prava i potpuno je jednako nasilju na ulicama.

Jedna od važnih činjenica koja se ne sme zanemariti je da strah od pojedinih gradskih zona i prostora, nije strah od same fizičke strukture, već od ljudi i njihovog ponašanja. Uočeno je da prostori koji izazivaju strah, nisu obavezno prostori u kojima se dešavaju incidenti, ali šanse da to postanu su zaista velike. Analiza prostora u kojima su počinjeni seksualni delikti, koja je sprovedena u Nemačkoj 1980. je pokazala da njihov tip i karakter (loše osvetljenje, mesta pogodna za skrivanje i prepad, izolovanost i sl.) upravo odgovara iskazanim strahovima. [14] Takođe, drugo istraživanje, takođe sprovedeno u Nemačkoj ukazalo je da oko 30\% seksualnih napada su izvršili počinioci koji ne žive blizu mesta napada, tj. da je oko $42 \%$ akta nasilja nad ženama izvršeno od strane počinioca koji su deo zajednice tj. susedstva. To postavlja pitanje da li žene treba više da se plaše poznatih od nepoznatih osoba? Bez obriza na to ko su počinioci i iz kojih sredina potiču, treba se skoncentrisati na prostore u kojima se incidenti dešavaju i eliminisati prilike koje im pogoduju. [15] Slični su rezultati studije sprovedene u Holandiji [16] Grad samo daje ili ne daje pogodno tlo za razvoj neženjenih događaja i kreiranje ličnog osećaja nebezbednosti.

Koncentracija na prevenciju nasilja je razumljiva, imajući u vidu podatak da je nasilje vodeći uzrok smrtnosti muškaraca i žena u starosnom dobu od 15 do 44 godine, te da teorijski može direktno ili indirektno da utiče na svakoga. [9] Prevencija je moguća, a njena cena je daleko manja od miliona dolara koje se širom sveta troše na snage policije, privatno obezbeđenje, sudstvo i sl. Ona zavisi isključivo od volje pojedinaca i zajednica, kao i od efektivnosti i demokratičnosti lokalne uprave. Prevencija nasilja [17] nije jednostavan zadatak, a posebno je teško znati odakle da se krene. Programi za procenu uspešnosti prevencije i u daleko razvijenijim zemljama, gde 
se već duži vremenski period primenjuju ovakve mere, su u početnim fazama i još uvek se razvijaju. Ali preovladava ubeđenje da prevencija smanjuje troškove društva, a svakako daje i dodatni kvalitet životu zajednice. Jedan od boljih pristupa je prethodna analiza razloga nastajanja nesigurnosti građana i prirode problema. Postoji izvesna kolektivna panika, vezana za određene pojave, na primer beskućnike ili teror maloletnih bandi. Sa druge strane, zajednica ponekada iz istih kulturoloških i moralnih razloga, odbija realnost postojanja opasnosti zloupotrebe dece ili homofobičnog nasilja. Često mediji [18] svojim prilozima utiču na kreiranje mišljenja javnosti, kako u pozitivnom smislu obaveštavanja i upozoravanja, tako i u negativnom kontekstu, izazivanjem panike i histerije.

\section{Reference:}

1. OECD: Pedestrian Safety, Urban Space and Health; International Transport Forum, 13 Aug 2012. http://www.oecd-ilibrary.org/transport/pedestrian-safety-urban-space-andhealth_9789282103654-en

2. Gehl J. Three types of outhdoor activities; Outdoor activities and quality of outdoor space. U: Carmona M, Tiesdell S, urednici. Urban design Reader. Architectural Press; 2007. p. 143-146.

3. Gehl J. Life Between Buildings, Using Public Space. The Danish Architectural Press; 2006.

4. Carr S, Francis M, Rivlin LG, Stone AM. Needs in public space. U: Carmona M, Tiesdell S, urednici. Urban design Reader. Architectural Press; 2007. p. 230-240.

5. El Fondo de la Vivienda del Instituto de Seguridad y Servicios Sociales de los Trabajadores del Estado. The Social Module of Housing. México; 1976.

6. Michelson W. Man and His Urban Environment. Reading, Mass: Addison-Wesley; 1970.

7. Ortiz de Urbina Gimeno I, Ponce Solé J. Convivencia ciudadana, seguridad pública y urbanismo, Diez textos fundamentales del panorama internacional. Barcelona: 2008.

8. Даниловић Христић Н. Урбанистичко-архитектонски елементи за обезбеђење вишег степена безбедности на јавним градским просторима, необјављена докторска дисертација, одбрањена на Архитектонском факултету Универзитета у Београду. 25.11.2010.

9. Whitzman C. The Handbook of Community Safety, Gender and Violence Prevention Practical Planning Tools. London: Earthscan; 2008.

10. Петровић М. Трансформација градова, ка деполитизацији урбаног питања. Београд: Институт за социолошка истраживања Филозофског факултета у Београду; 2009.

11. Wood P, Landry C. The intercultural City - Planning for Diversity Advantage. London: Earthscan; 2008.

12. Byrne D. Understanding the Urban. Palgrave; 2000.

13. Svensen LFH. Filozofija straha. Beograd: Geopoetika; 2008.

14. Gensch V, Zimmer B. Gewalt gegen Frauen in Kasse: Arbeitsbericht des Fachbereichs Stadt und Landschaftsplannung. Kassel: Gesamthochschule; 1980.

15. Metz G, Rijpkema H. Mythen en feiten over verkrachting. Groningen; 1979. 
16. Loef CJ. Aanranding en verkrachting: Gemeente Amsterdam. Amsterdam: Bestuursinformatie, afd. onderzoek en statistiek; 1985.

17. Schneider RH, Kitchen T. Crime Prevention and the Built Environment. London: Routledge; 2007.

18. Reiner R. Media-made criminality: the retresentation of crime in the mass media. U: Maguire M, Morgan R, Reiner R, urednici. The Oxford Handbook of Criminology. Oxford University Press; 2007. 303-337.

\section{Summary}

The World Health Organization (WHO) classifies community safety of crime in the category of natural disasters, fires, traffic and other accidents, in which the major role is played by the ability of the community to react, prevent, help or reduce negative effects. Also, The International Centre for the Prevention of Crime gives even wider focus on community safety, considering it as a public good. One of the generally accepted definitions that "the safety it the basis is the freedom of the threats", which gives interpretation on higher level of overall safety (state, national), but it could be adapted on the level of urban space and feelings of its users. The basis for violent (criminal, sexist or racist) behavior toward some distinct categories of the population lays in general social and economic situation of the society, which is transferred to city streets. The reality and seriousness of the street violence leads to general feeling of the insecurity in communities and insecurity of urban spaces, which leads to its reduced use. There is an increase of clinic cases of the contemporary urban disease of agoraphobia, that originally signified fear of open space, but nowadays the implications of this term are the assemblage of fears in connection with the open spaces and great amount of people and the fear of suddenly incapacity to run away or seek for help. It is necessary to define and establish the conditions for the community safety in order to receive the positive result of the crime prevention; in order to be treated as the aspect of the quality of life, in which the people, individually or collectively, are in best possible way protected of potential dangers or threats that are consequences of the criminal or antisocial behavior of other parts of society. The sense of insecurity in the public urban spaces has two dimensions, the objective and subjective. The objective is supported by realistic events in space and subjective is topic of the personal feelings of the citizens, based equally on objective dimension as on single rating of the acceptance and tolerance of reality, weakness or courage, readiness to resist and to oppose to the violence in surrounding. How one person will react depends of the development of his/ her senses, which are partially destined by the social status.

Rad primljen: 12. 5. 2014 .

Recenziran: 9. 7. 2014.

Prihvaćen: 11. 8. 2014. 